\title{
Novelty of contextual cues in taste aversion learning
}

\author{
ELIZABETH M. KURZ and DAVID A. LEVITSKY \\ Cornell University, Ithaca, New York
}

\begin{abstract}
The purpose of this experiment was to test the theory of Lubow, Rifkin, and Alek (1976) concerning the effects of stimulus preexposure on later learning. This hypothesis predicts that conditioning will occur faster when either the stimulus or the testing environment is novel relative to the other than when the stimulus and the environment are equally novel or equally familiar. The theory was tested in a taste aversion conditioning paradigm in which groups of rats were presented with either the familiar (preexposed) solution or the novel nonpreexposed solution, in either the familiar or the novel environment. Conditioning was affected by the novelty of both the stimulus and the environment, with novel stimuli enhancing learning and novel environ. ments retarding it. However, no interaction between stimulus and environmental novelty was evident, and thus Lubow's hypothesis was not confirmed.
\end{abstract}

There is little question of the powerful effect of stimulus preexposure on subsequent tests of learning in animals. However, there is a problem in our understanding of why stimulus preexposure in certain circumstances leads to slower learning, as in latent inhibition (Lubow, 1973), and in other situations leads to an increase in the rate of learning, for example, perceptual learning (Hall, 1980; Tees, 1976) or latent learning (Kimble, 1961).

In an attempt to explain this paradox, Lubow and his associates (Lubow, Rifkin, \& Alek, 1976) suggested a fundamental methodological distinction between latent inhibition and perceptual (stimulus) learning experiments. In the typical latent inhibition experiment, the experimental groups are taken out of their home cages and exposed to the test stimulus in the test environment. Thus, this group becomes familiar with both the stimulus and the environment, $\mathrm{S}_{\mathrm{f}} \mathrm{E}_{\mathrm{f}}$. The control group is also exposed to the test apparatus, but is not exposed to the test stimulus. During testing, therefore, this group receives a novel stimulus in a familiar environment, $S_{n} E_{f}$. Latent inhibition is defined by more rapid learning of a problem by the control group, $S_{n} E_{f}$, than by the experimentals, $S_{\mathrm{f}} \mathrm{E}_{\mathrm{f}}$.

On the other hand, in the typical perceptual learning experiment, the experimental group is exposed to and becomes familiar with the test stimuli in their home cages, but are tested in a new environment, $\mathrm{S}_{\mathrm{f}} \mathrm{E}_{\mathrm{n}}$. The control group in these experiments receives no such stimulus preexposure and, thus, during testing, both the stimuli and the test environment are

Research supported in part by Grant BNS 7812531 from the National Science Foundation and from Hatch funds. The authors are associated with the Department of Psychology and the Division of Nutritional Sciences, Cornell University, Ithaca, New York 14853. new, $S_{n} E_{n}$. Latent learning or perceptual learning is defined by more rapid learning by the experimental group, $S_{\mathrm{f}} E_{n}$, than by the controls, $S_{n} E_{n}$.

These procedural differences led Lubow and his associates to suggest that stimulus preexposure results in faster, stronger learning when, during testing, either the stimulus or the environment is novel relative to the other. Situations which do not contain this contrast in the level of novelty $\left(S_{f} E_{f}\right.$ or $\left.S_{n} E_{n}\right)$ should produce slower, weaker learning. Lubow et al. (1976) obtained supporting evidence for this hypothesis in two discrimination experiments which used approach responses as a measure of learning. In one of these experiments, rats were trained to approach a familiar or novel odor for food reinforcement in a modified Y-maze. The other experiment used an identical design, with children as subjects. It is interesting to note that these results also support Wagner's $(1976,1978)$ learning model involving the effect of contextual cues on conditioning.

The purpose of the present investigation was to test Lubow's hypothesis of stimulus preexposure, using a conditioned taste aversion paradigm. In the present study, both the novelty of a flavored solution and the novelty of the testing environment (context) were manipulated, and their effect on a conditioned taste aversion to the flavor were examined. If the hypothesis of Lubow et al. (1976) was correct, a novel-tasting solution should produce strong conditioning in a familiar environment $\left(S_{n} E_{f}>S_{f} E_{f}\right)$ but weak conditioning in a novel environment $\left(S_{\mathrm{f}} E_{n}>S_{n} E_{n}\right)$.

\section{METHOD}

\section{Subjects}

The subjects were 80 male Long-Evans hooded rats approximately 6 weeks old and weighing $135-222 \mathrm{~g}$ at the beginning of the experiment. They were housed singly under a reversed lighting cycle 
Table 1

Experimental Design

\begin{tabular}{|c|c|c|c|}
\hline & Phase & Days & $\begin{array}{l}\text { Stimulus and Environ- } \\
\text { ment Conditions }\end{array}$ \\
\hline I. & Preexposure & $1-14$ & $S_{f} E_{f}$ \\
\hline II. & Conditioning & 15 & $S_{f} E_{f}, S_{f} E_{n}, S_{n} E_{f}, S_{n} E_{n}$ \\
\hline HI. & Rest & 16 & $\mathrm{~S}_{\mathrm{f}} \mathrm{E}_{\mathbf{f}}$ \\
\hline IV. & Conditioning & 17 & $S_{f} E_{f}, S_{f} E_{n}, S_{n} E_{f}, S_{n} E_{n}$ \\
\hline V. & Testing & $18-19$ & $S_{f} E_{f}, S_{f} E_{n}, S_{n} E_{f}, S_{n} E_{n}$ \\
\hline
\end{tabular}

Note $-S=$ stimulus, $E=$ environment $f=$ familiar,$n=$ novel .

(12 h light, $12 \mathrm{~h}$ dark). All subjects had ad-lib access to Purina Lab Chow throughout the experiment, and $12 \mathrm{~h}$ access per day (during the dark half of their cycle) to water and/or another fluid, depending on the experimental procedure.

\section{Procedure}

The basic sequence of events is shown in Table 1. The first phase of the experiment, the preexposure phase, ran from Day 1 to Day 14 of the experiment. For this phase, each animal was assigned randomly to one of the two types of environment (a $24 \times$ $18 \times 18 \mathrm{~cm}$ cage made of wire mesh or solid metal) and to one of the two stimuli (vanilla or anise solution, $.2 \% \mathrm{v} / \mathrm{v}$ ), such that the four resulting groups had 20 subjects each. During the preexposure period, each animal had access to a bottle of tap water and a bottle of its assigned solution for the 12-h fluid-access period each day. Fluid intakes and body weights were recorded daily.

For the first conditioning session, on Day 15 of the experiment, each of the four major groups of the preexposure period was divided into four subgroups ( $n=5$ in each subgroup) corresponding to the four groups in Table 1. For example, of the group that had been preexposed to the vanilla solution in wire-mesh cages, five animals were conditioned with the vanilla solution in the same mesh cages $\left(S_{f} E_{f}\right)$, another five were so conditioned in a novel solid metal cage $\left(S_{\mathrm{f}} \mathrm{E}_{\mathrm{n}}\right)$. In the conditioning procedure itself, each animal was given access to the appropriately flavored solution alone for $1 / 2 \mathrm{~h}$ in the appropriate type of cage. It was then injected intraperitoneally with $2 \mathrm{cc} / 100 \mathrm{~g}$ body weight of a $.15 \mathrm{M}$ lithium chloride $(\mathrm{LiCl})$ solution and returned to its home cage, where it received tap water only for the remainder of the usual 12-h period. On the following day, the animals remained in their home cages and received the same fluids they had received on Day 14 . The second conditioning session on Day 17 of the experiment followed exactly the same procedure as the one just described. All animals received the same treatment $\left(S_{f} E_{f}, S_{f} E_{n}, S_{n} E_{f}, S_{n} E_{n}\right)$ on Day 17 they had received on Day 15. Two conditioning sessions were employed to ensure an observable conditioning effect, given the fact that a stimulus other than a taste (i.e., a novel environment) was being manipulated as a possible conditioned stimulus (CS). It has been reported (e.g., Mitchell, Kirschbaum, \& Perry, 1975) that when using an exteroceptive $\mathrm{CS}$ with $\mathrm{LiCl}$ as the unconditioned stimulus (US), more than one conditioning trial may be necessary.

For the testing days, which immediately followed the second conditioning day, each animal was exposed to the environment and to the flavor it had experienced during conditioning. It was given a bottle of plain tap water and a bottle of the appropriately flavored solution. Its intake from both bottles was recorded after $1,2,3,4$, $5,6,8,10$, and $12 \mathrm{~h}$ on the first test day (Day 18). The animals were reexposed to the testing situation on Day 19, and their intakes of water and of the solution were recorded after $12 \mathrm{~h}$ of access.

\section{RESULTS AND DISCUSSION}

A preliminary analysis of variance (ANOVA) showed no significant effects of the kind of solution (vanilla or anise flavor) or the kind of cage (solid metal or wire mesh) to which the rats were exposed on the test days. Therefore, in all subsequent analyses, the data were summed over these factors.

Table 2 shows the overall intake of the flavored solution on the 2 test days, broken down by treatments $\left(S_{f} E_{n}, S_{n} E_{n}\right.$, etc.). The data were analyzed in terms of absolute intake; however, the same pattern of results was evident when the data were expressed as the percentage of the total fluid consumed as the test solution. A $2 \times 4$ ANOVA revealed a significant effect of treatment $[F(3,76)=3.33$, $p<.05$, twotailed] and a marginally significant decrease in intake between the first and second test days $[F(1,76)=3.08$, $.10>\mathrm{p}>.05$, two-tailed], but no significant interaction.

The comparison of the test-day data with preexposure intake demonstrates that all groups except the $\mathrm{S}_{\mathrm{f}} \mathrm{E}_{\mathrm{n}}$ showed a significant depression in intake on the first test day, indicating strong conditioning. Comparing the flavored solution intake from the first test day with the average intake over the last 3 preexposure days, the following results were obtained: for $S_{f} E_{f}, t(19)=2.94, p<.01$; for $S_{n} E_{f}, t(19)$ $=3.95, p<.002$; for $S_{n} E_{n}, t(19)=3.22, p<.005$; for $\mathrm{S}_{\mathrm{f}} \mathrm{E}_{\mathrm{n}}, \mathrm{t}(19)=.490$, n.s.

The next major analysis performed on the data examined the overall effects of familiar or novel stimuli and familiar or novel environments on intake of the flavored solutions on the first test day. The results of the analysis are presented in Figure 1. As indicated by a significant main effect of stimulus novelty/ familiarity $[F(1,76)=4.89, p<.05]$, it is clear that a novel stimulus significantly enhances conditioning. This is in agreement with observations made by others (e.g., Kalat \& Rozin, 1973; Revusky \& Bedarf, 1967; Siegel, 1974).

The most important point, however, is that the data clearly fail to confirm Lubow's hypothesis concerning the latent inhibition and perceptual learning effects. It should be recalled that Lubow's hypothesis predicts better conditioning resulting from a novel stimulus presented in a familiar environment. On the other hand, in a novel environment better conditioning should occur with familiar stimuli. The data indicate that conditioning was enhanced in a familiar en-

Table 2

Mean Intake of Flavored Solution

\begin{tabular}{|c|c|c|c|c|c|c|}
\hline \multirow{3}{*}{$\begin{array}{l}\text { Treat- } \\
\text { ment }\end{array}$} & \multicolumn{6}{|c|}{ Intake (in Milliliters) } \\
\hline & \multicolumn{2}{|c|}{ Baseline } & \multicolumn{2}{|c|}{ Test Day 1} & \multicolumn{2}{|c|}{ Test Day 2} \\
\hline & Mean & $\mathrm{SE}$ & Mean & SE & Mean & $\mathrm{SE}$ \\
\hline$S_{f} E_{f}$ & 11.2 & .939 & 6.3 & 1.54 & 4.9 & 1.56 \\
\hline$S_{f} E_{n}$ & 10.5 & .760 & 11.3 & 2.50 & 7.6 & 1.83 \\
\hline$S_{n} E_{f}$ & 11.2 & 1.01 & 4.3 & 1.32 & 2.8 & .917 \\
\hline$S_{n} E_{n}$ & 11.4 & .986 & 6.4 & 1.49 & 4.6 & 1.40 \\
\hline
\end{tabular}



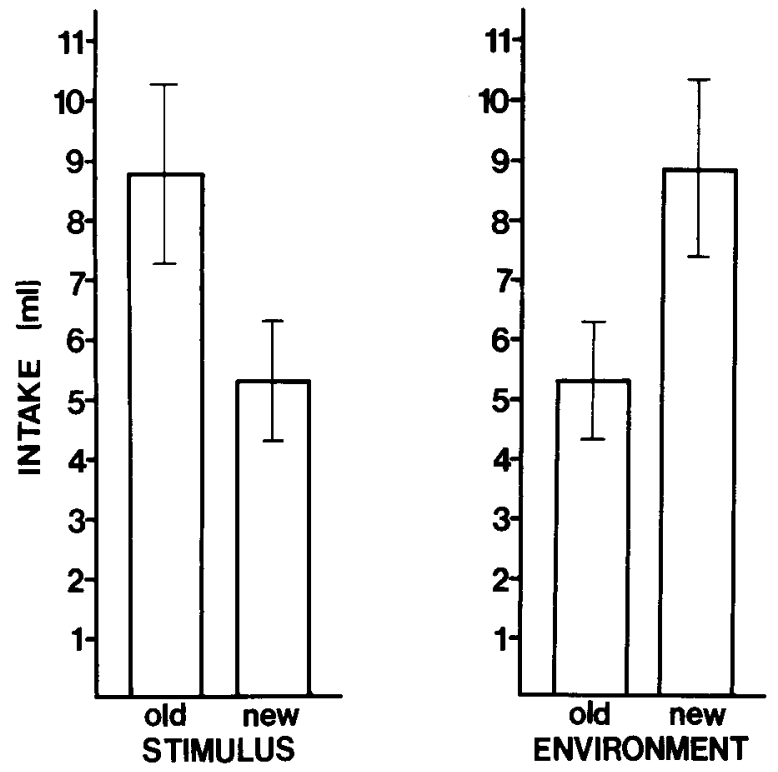

Figure 1. Mean intake (with standard error) of the flavored solution in milliliters on the first test day, presented as a function of the stimulus conditions (on the left) and environmental conditions (on the right).

vironment $[F(1,76)=4.61, p<.05]$, but, as indicated by a lack of statistical interaction between the stimulus and environmental factors $[F(1,76)=.478$, n.s. $]$, the enhancing effect of a novel stimulus on conditioning occurred to about the same degree in both novel and familiar environments. Neither the stimulus nor the environmental factors interacted with the test days factor, indicating that the same pattern of results occurred on both test days.

It should be noted that conditioning was poorer in a novel environment than in a familiar one. One explanation may lie in the fact that during conditioning sessions, the animals in novel environments consumed less than did the rats in familiar environments; in the novel environments, an average of $5.01 \mathrm{ml}$ of the flavored solutions were consumed, compared with $6.97 \mathrm{ml}$ in the familiar environments. A similar effect of novel environments on consummatory behavior has been noted by others (Bolles \& Rapp, 1965; Moll, 1959; Welker, 1959). Moreover, it is known that the strength of a taste aversion is a direct function of the amount of fluid consumed during conditioning (Barker, 1976; Bond \& DiGiusto, 1975). However, the correlation between conditioning day intake and test day intake in our data is approximately .26 , which implies that variations in intake during the conditioning sessions account for only $7 \%$ of the variance in test day intake. This analysis, therefore, suggests that the disruptive effect of novel environments on taste aversion learning is greater than can be accounted for merely by the differences in fluid intake during conditioning. Some other factor, such as distraction by novel stimuli, must be operating in this situation.

The relationships between novelty, context, and conditioning are addressed in a theory recently proposed by Wagner $(1976,1978)$. This theory suggests (in part) that contextual or environmental cues can be associated with particular conditioned stimuli (CSs) such that when the contextual cues are presented, they can activate the memory of the associated CS and "prime" it into short-term memory (STM). When the memory of the CS is represented in STM, it is "expected," according to Wagner's theory, and therefore cannot support strong conditioning. On the other hand, if an animal is presented with a previously exposed stimulus in a novel context (or any context other than that in which the stimulus was exposed), the stimulus should be unexpected and thereby be able to promote strong conditioning. Similarly, if a novel (unexpected) stimulus is presented in a familiar context, conditioning should also occur. In the present experiment, Wagner's theory would predict strong conditioning in both the $S_{n} E_{f}$ and the $S_{f} E_{n}$ conditions. Our failure to obtain conditioning in the latter group casts some doubt on the general applicability of Wagner's theory.

The present results clearly support the emphasis placed by both Lubow and Wagner on the importance of contextual cues in conditioning. However, these results also imply that the particular manner through which contextual cues may affect conditioning may be dependent upon the specific learning problem confronting the organism.

\section{REFERENCES}

BARKER, L. M. CS duration, amount, and concentration effects in conditioning taste aversions. Learning and Motivation, 1976, 7, 265-273.

Bolles, R. C., \& RAPP, H. M. Readiness to eat and drink: Effect of stimulus conditions. Journal of Comparative and Physiological Psychology, 1965, 60, 93-97.

Bond, N., \& DiGiusto, E. Amount of solution drunk is a factor in the establishment of taste aversions. Animal Learning \& Behavior, 1975, 3, 81-84.

Hall, G. Exposure learning in animals. Psychological Bulletin, $1980,88,535-550$.

Kalat, J. W., \& Rozin, P. "Learned safety" as a mechanism in long-delay taste aversion in the rat. Journal of Comparative and Physiological Psychology, 1973, 83, 198-207.

Kimble, G. A. Hilgard and Marquis' conditioning and learning. New York: Appleton-Century-Crofts, 1961.

Lubow, R. E. Latent inhibition. Psychological Bulletin, 1973, 79, 398-407.

Lubow, R. E., Rifkin, B., \& Alek, M. The context effect: The relationship between stimulus preexposure and environmental preexposure determines subsequent learning. Journal of Experimental Psychology: Animal Behavior Processes, 1976, 2, 38-47.

Mitchell, D., Kirschbaum, E. H., \& Perry, R. L. Effects of neophobia and habituation on the poison-induced avoidance of exteroceptive stimuli in the rat. Journal of Experimental Psychology: Animal Behavior Processes, 1975, 104, 47-55. 
Molt, R. P. The effect of drive level on acquisition of the consummatory response. Journal of Comparative and Physiological Psychology, 1959, 52, 116-119.

Revusky, S. H., \& Bedarf, E. W. Association of illness with prior ingestion of novel foods. Science, 1967, 155, 219-220.

SIEGEL, S. Flavor preexposure and "learned safety." Journal of Comparative and Physiological Psychology, 1974, 87, 1073-1082.

TEEs, R. C. Perceptual development in mammals. Studies on the Development of Behavior and the Nervous System, 1976, 3, 281-326.

Wagner, A. R. Priming in STM: An information-processing mechanism for self-generated or retrieval-generated depression in performance. In T. J. Tighe \& R. N. Leaton (Eds.), Habituation. Hillsdale, N.J: Erlbaum, 1976.

WAgner, A. R. Expectancies and the priming of STM. In S. H. Hulse, H. Fowler, \& W. K. Honig (Eds.), Cognitive processes in animal behavior. Hillsdale, N.J: Erlbaum, 1978.

WELKER, W. I. Escape, exploratory, and food-seeking responses of rats in a novel situation. Journal of Comparative and Physiological Psychology, 1959, 52, 106-111.

(Manuscript received July 13, 1981; revision accepted for publication November 6,1981 .) 